\title{
Type 2 diabetes: cost-effectiveness of medication adherence and lifestyle interventions
}

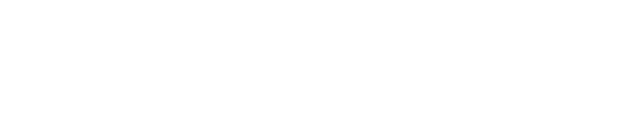

\section{Tomaž Nerat Igor Locatelli Mitja Kos}

Faculty of Pharmacy, University of Ljubljana, Ljubljana, Slovenia
Correspondence: Tomaž Nerat University of Ljubljana, Faculty of Pharmacy, Aškerčeva cesta 7 , SI-I 000 Ljubljana, Slovenia $\mathrm{Tel}+386$ 3I 868627 Email tomaz.nerat@gmail.com
Introduction: Type 2 diabetes is a major burden for the payer, however, with proper medication adherence, diet and exercise regime, complication occurrence rates, and consequently costs can be altered.

Aims: The aim of this study was to conduct a cost-effectiveness analysis on real patient data and evaluate which medication adherence or lifestyle intervention is less cost demanding for the payer.

Methods: Medline was searched systematically for published type 2 diabetes interventions regarding medication adherence and lifestyle in order to determine their efficacies, that were then used in the cost-effectiveness analysis. For cost-effectiveness analysis-required disease progression simulation, United Kingdom Prospective Diabetes Study Outcomes model 2.0 and Slovenian type 2 diabetes patient cohort were used. The intervention duration was set to 1,2, 5 , and 10 years. Complications and drug costs in euro (EUR) were based on previously published type 2 diabetes costs from the Health Care payer perspective in Slovenia.

Results: Literature search proved the following interventions to be effective in type 2 diabetes patients: medication adherence, the Mediterranean diet, aerobic, resistance, and combined exercise. The long-term simulation resulted in no payer net savings. The model predicted following quality-adjusted life-years (QALY) gained and incremental costs for QALY gained (EUR/QALYg) after 10 years of intervention: high-efficacy medication adherence (0.245 QALY; 9,984 EUR/QALYg), combined exercise (0.119 QALY; 46,411 EUR/QALYg), low-efficacy medication adherence (0.075 QALY; 30,967 EUR/QALYg), aerobic exercise (0.069 QALY; 80,798 EUR/QALYg), the Mediterranean diet (0.057 QALY; 27,246 EUR/QALYg), and resistance exercise (0.050 QALY; 111,847 EUR/QALYg).

Conclusion: The results suggest that medication adherence intervention is, regarding costeffectiveness, superior to diet and exercise interventions from the payer perspective. However, the latter could also be utilized by patients without additional costs, but medication adherence intervention requires trained personnel because of its complex structure. Interventions should be performed for $>2$ years to produce noticeable health/cost results.

Keywords: type 2 diabetes, adherence, intervention, medication, lifestyle, cost-effectiveness

\section{Introduction}

Type 2 diabetes is a major health care burden for the payer. In the scope of global estimates, the prevalence will rise and consequently the costs. ${ }^{1,2}$ The disease incidence, prevalence, progression, and complication occurrence are dependent on a number of factors: weight, fat distribution, fasting glucose, glycated hemoglobin (HbA1c), blood lipids, blood pressure, physical inactivity, family history, race, and age. ${ }^{3}$ Therefore, accurate drug regime adherence and improved lifestyle regarding diet and exercise are the key to decelerate the disease progression and the incidence 
of complications. As a result, disease costs can be altered. Major trials were performed to assess the impact of lower blood glucose levels, lower blood pressure and lower lipid levels on disease progression and occurrence of microvascular and macrovascular complications. ${ }^{4}$ The ACCORD, ADVANCE, and VADT studies focused on single risk factor enhancements (blood glucose and lipid lowering) and concentrated on achieving tight glucose control in a short time. However, primary results have not demonstrated any reduction of complications occurrence or mortality. ${ }^{4-9}$ In ACCORD's follow-up study, it was revealed that lowering $\mathrm{HbA} 1 \mathrm{c}$ to $<7 \%$ actually reduced the mortality rate. Furthermore, the mortality rate increased linearly from $6 \%$ to $9 \% \mathrm{HbA}_{1 \mathrm{c} .}{ }^{10}$ The positive effect of a lower HbA1c on cardiovascular complications (the United Kingdom Prospective Diabetes Study [UKPDS], HOPE study) was also detected in long-term epidemiological studies. ${ }^{11-14}$ The intervention results in type 2 diabetes patients, however, strongly indicated that all three risk factors (glucose levels, lower blood pressure, and lower levels of cholesterol) should be targeted to achieve optimal diabetes progression reduction and complications occurrence reduction. ${ }^{4}$ Consequently, the Steno study was conducted. ${ }^{15,16}$ In the study, $\mathrm{HbA1c}$, total cholesterol, and serum triglycerides were used as primary outcome measures. The results confirmed that type 2 diabetes complication occurrence rate drops were significantly higher than those reported in studies employing single risk factor control interventions, suggesting that with proper multifactorial interventions, diabetes outcomes and payer burden can be altered. ${ }^{4}$ As noted previously, interventions regarding medication adherence and lifestyle (diet and exercise) are suitable to alter multiple diabetes risk factors, especially the $\mathrm{HbA} 1 \mathrm{c}$, high-density lipoprotein (HDL), low-density lipoprotein (LDL), weight, and blood pressure values. ${ }^{17-20}$

The aim of the present study was therefore to conduct a cost-effectiveness analysis on real patient data and evaluate which medication adherence or lifestyle intervention to choose, when to apply it, and which one is less cost demanding for the payer with the help of quality-adjusted life-years (QALYs) gained and cost increment predictions.

\section{Methods}

To conduct a cost-effectiveness analysis of medication adherence and lifestyle interventions on real patient data, the literature was searched for relevant interventions and their efficacy, eligible simulation software, intervention costs, type 2 diabetes complication costs, and drug costs. The steps taken in the study are detailed as follows.

\section{Search strategy and study selection for intervention assessment}

Search key (type 2 diabetes) AND (exercise OR workout OR diet OR dietary OR diets OR adherence OR compliance) AND (intervention OR interventions) AND (meta OR review) were used on Medline database to search for possible interventions and their efficacies. Date of publication was not limited. Studies that clearly assessed medication adherence and lifestyle interventions and consequently allowed to quantitatively determine effectiveness of each intervention were included. Studies that encompassed interventions regarding behavior changes for intervention efficacy enhancing, interventions encompassing gestational diabetes, depression, diabetes prevention, risk of diabetes, schizophrenia, children, adolescents, type 1 diabetes, kidney diseases, dialysis, and transplantation were excluded. Based on the written protocol for review, one reviewer assessed titles and abstracts of all the retrieved articles. Abstracts that did not provide enough information regarding the eligibility criteria were retrieved for full-text evaluation. The full-texts of selected articles were also evaluated on the basis of the eligibility criteria. The final selection was checked and discussed with other authors.

\section{Simulation model used}

The UKPDS Outcomes model 2.0 was used for type 2 diabetes progression simulations. ${ }^{21}$ The model predicts future events year by year, based on a series of risk equations, derived from the initial UKPDS cohort. The key aspect of the model is its ability to capture the clustering or interaction of different types of complications at an individual patient level. It also allows modification of various type 2 diabetes risk factor values for any given patient life year. Therefore, the model is suitable for the present cost-effectiveness assessment, as different durations of interventions could be simulated. Regarding the Fifth Mount Hood challenge, the UKPDS Outcomes model performs reasonably well when performing relative risk simulations. In addition, it also predicted higher cardiovascular mortality correctly with relation to aggressive HbA1c and blood pressure control, which the other models did not. ${ }^{22}$

The simulation software allows the use of multiple computer processor cores. However, the results differ slightly regarding the number of cores used. Our calculations were conducted with Xeon 1231v3 processor with seven logical 
cores used, the number of loops value was set to 10,000 and the bootstraps value was set to 999 . These settings produced stable results with a relative error of $<5 \%$ (obtained from model results).

The study was performed from the Slovenian Health Care payer perspective. The latter consists of The Health Insurance Institute of Slovenia as compulsory health insurance and several complementary insurances. The patients were followed up for a lifetime. Outcomes were simulated in yearly cycles and included model-provided QALYs gained and costs in euros (EUR) as results, with a 5\% annual discount rate for both. The outcomes were expressed as an incremental cost-effectiveness ratio (ICER) in EUR per QALY gained (EUR/QALYg) for each intervention type and their duration compared to no intervention.

Because of different intervention durations, we decided to simplify and assumed that each intervention lasted 1 year, although two diet and one exercise interventions were previously conducted for 2 years and 4 years, respectively. ${ }^{23-25}$ Therefore, to simulate an intervention effect for multiple years, the intervention had to be repeated annually. In our case, simulations were conducted for 1 and 2 years of intervention duration to capture the effects based on published studies and for 5 and 10 years to predict the possible effects with longer intervention duration. A longer intervention inclusion was possible because duration of intervention was not among predictors of dropout in long-term disease care program and short-term interventions according to published data. ${ }^{26-29}$

\section{Cost-effectiveness of different interventions}

\section{Patient data}

Individual patient data were obtained in advance from the Slovenian pharmacist intervention study presented at the National Diabetes Conference in 2014 where 93 type 2 diabetes patients were recruited. ${ }^{30}$ The mean (standard deviation) age of the patients was 65.9 (7.5) years which was therefore higher than that researched before in Slovenia [59 (10.1) and 62.2 years]; however, other diabetes risk factors were comparable. ${ }^{31,32}$ Average $\mathrm{HbA} 1 \mathrm{c}$ values from our cohort were $0.1 \%$ higher; HDL $0.03 \mathrm{mmol} / \mathrm{L}$, and LDL $0.61 \mathrm{mmol} / \mathrm{L}$ lower; and systolic blood pressure $2 \mathrm{mmHg}$ higher, and therefore, despite different average age, the values were generally similar. ${ }^{31,32}$ Outcomes model 2.0 is based on new onset diabetes patients (mean age 53 years) who were followed-up for 25 years (intervention median of 16.8 and 17.7 years, posttrial 8.5 and 8.8 years, respectively). Therefore, a simulation with patients of higher age is possible. ${ }^{33}$ The heart rate, WBC count, hemoglobin, and estimated eGFR were not obtained from the patients, because at the time of the Slovenian intervention study the required input values for UKPDS Outcomes model 2.0 were not published. Therefore, published mean values were used and were adjusted to individual patients for outcomes model internal equations. ${ }^{34-37}$ Patient demographic data are presented in the "Results" section.

\section{Costs and utilities of diabetes complications and medications}

Previously published type 2 diabetes costs from the Health Care payer perspective in Slovenia were used to assess the cost values of diabetes complications and medication. ${ }^{38}$ The published costs were valid for the year 2011. Therefore, an update with recent Health Care payer data was conducted. All 2015 costs were lower than the 2011 costs, in particular the medication expenses. The assessed costs for the year 2015 are presented in Table S1. The prices of statins, ACE inhibitors, beta blocking agents, and acetylsalicylic acid fell by $60 \%, 40 \%$, and $20 \%$, respectively, from 2011 to $2014 .{ }^{39}$ The cost of the antidiabetics and insulin, however, fell only by $6 \%{ }^{39}$ The medication cost reduction calculation is provided in detail in the Supplementary materials.

For utility decrements, UKPDS Outcomes model 2.0published values were used (presented in Table S1).

\section{Intervention costs}

Previously published data were used to assess the intervention costs. For the medication adherence intervention, baseline costs of 329 EUR for 1 year of intervention duration (currency conversion on March 15, 2016: USD411.5) were used. ${ }^{40}$ The costs were further inflated by higher drug consumption (52 EUR for high-efficacy adherence intervention and 13 EUR for low-efficacy adherence intervention). Higher adherence costs were derived from baseline drug costs (283.40 EUR) with the consideration of high and low adherence enhancement (20\% vs 5\%). ${ }^{41}$ Cost of 232 EUR per patient was used for the diet intervention, whereas $800 \mathrm{EUR}$ per patient was used for the exercise intervention. ${ }^{42,43}$

\section{Sensitivity analysis}

For the univariable sensitivity analysis, the impact of the variability of model parameters over their plausible ranges was tested. The one-way analysis for 2-year intervention duration was performed on discount rate $(0 \%$ or $7 \%)$, intervention costs $(-10 \%,+10 \%)$, and complication costs $(-10 \%,+10 \%)$. 
The 2-year duration was chosen because it is supported by published data, whereas 5- and 10-year intervention durations are predictions.

\section{Results}

\section{Description of studies selected for} medication adherence and lifestyle intervention cost-effectiveness analysis

In the initial search on Medline (January 1, 2016), 1,360 potentially relevant citations were retrieved, from which 52 articles were subjected to full-text review after title and abstract screening. After the review, 20 met the inclusion criteria. One of them was attributed to medication adherence, ten to diet lifestyle interventions, and nine to exercise lifestyle interventions. ${ }^{41,44-62}$ The interventions are presented in detail with a flow diagram in Figure 1.

\section{Medication adherence interventions}

Retrieved studies encompassed the following intervention subtypes: simplification of drug regimen; patient education and information; intensified patient care, with reminders via mail, telephone, or handheld devices; Internet-based programs; home telehealth devices and also complex behavior approaches with or without group sessions. ${ }^{41}$ The duration of the studies ranged from a few weeks to 2 years. Diverse intervention approaches prevented the authors from conducting a meta-analysis. ${ }^{41}$ Therefore, highest and lowest ranges of $\mathrm{HbA} 1 \mathrm{c}$ reduction $(-1.5 \%$ to $-0.5 \%)$ were utilized for the costeffectiveness analysis. ${ }^{41}$ Upper and lower HDL, LDL, blood pressure, and weight changes were derived from reviews that were cross-referenced with the selected articles, by us. ${ }^{18-20}$ In all the interventions, the common factor was that the intervention effects lasted for the duration of the intervention. After cessation, the effects disappeared. ${ }^{41}$ It was assumed that the effect disappearance occurs shortly after conclusion of the intervention because after the UKPDS intensive therapy intervention had ended, the between-group difference in glycated hemoglobin was lost in the following year. ${ }^{13}$ Different intervention efficacies for HbA1c, LDL, HDL, weight, and blood pressure are summarized in Table 1.

\section{Diet lifestyle interventions}

Diet interventions were divided into low carbohydrate, high protein, (very) low glycemic index, low-fat, ADA, conventional, the Mediterranean, and vegetarian diets. ${ }^{44-53}$ However, conventional, low-fat, ADA and low glycemic index diets were utilized as reference or control diets. Ajala et al conducted the first meta-analysis of different diets and reported their impact on glycemic control, weight, and blood lipids. ${ }^{44}$ The meta-analysis was conducted with

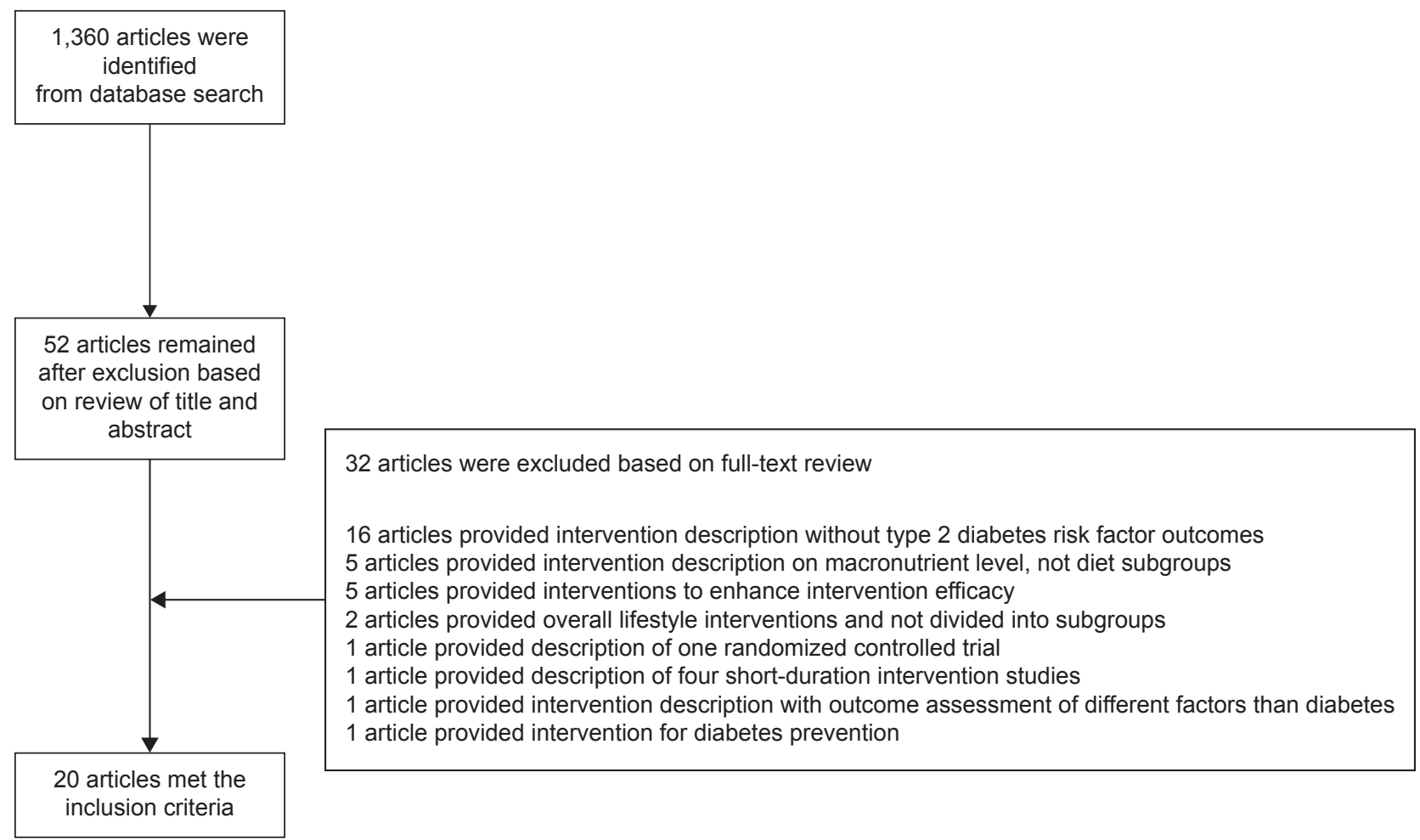

Figure I Flow diagram of literature search and study selection. 
Table I Medication adherence and lifestyle intervention effects on HbAIc, HDL, LDL, weight, and blood pressure values

\begin{tabular}{|c|c|c|c|c|c|}
\hline \multirow[t]{2}{*}{ Intervention } & \multicolumn{5}{|c|}{ Intervention outcome on diabetes risk factors } \\
\hline & HbAlc (\%) & $\begin{array}{l}\text { HDL } \\
(\mathrm{mmol} / \mathrm{L})\end{array}$ & $\begin{array}{l}\text { LDL } \\
(\mathrm{mmol} / \mathrm{L})\end{array}$ & Weight (kg) & $\begin{array}{l}\text { Blood pressure } \\
(\mathrm{mmHg})\end{array}$ \\
\hline $\begin{array}{l}\text { Medication adherence } \\
\text { (high efficacy) }\end{array}$ & $-1.5^{41}$ & $0.122^{18}$ & $-0.714^{18}$ & $-5 \%^{20}$ & $-8.6^{19}$ \\
\hline $\begin{array}{l}\text { Medication adherence } \\
\text { (low efficacy) }\end{array}$ & $-0.5^{41}$ & $0.00259^{18}$ & $-0.134^{18}$ & $-1 \% 20$ & $-3.5^{19}$ \\
\hline $\begin{array}{l}\text { The Mediterranean } \\
\text { diet }\end{array}$ & $\begin{array}{l}-0.3 \\
(-0.46,-0.14)^{48}\end{array}$ & $\begin{array}{l}0.06 \\
(0.02,0.10)^{48}\end{array}$ & $\begin{array}{l}-0.11 \\
(-0.24,0.01)^{48}\end{array}$ & $\begin{array}{l}-0.29 \\
(-0.55,-0.04)^{48}\end{array}$ & $\begin{array}{l}-1.7 \\
(-3.3,-0.05)^{66}\end{array}$ \\
\hline Aerobic exercise & $\begin{array}{l}-0.46 \\
(-0.71,-0.22)^{55}\end{array}$ & $\begin{array}{l}0.02 \\
(-0.01,0.06)^{55}\end{array}$ & $\begin{array}{l}-0.14 \\
(-0.32,0.06)^{55}\end{array}$ & $\begin{array}{l}-0.53 \\
(-0.81,-0.26)^{55}\end{array}$ & $\begin{array}{l}-1.66 \\
(-4.99,1.67)^{55}\end{array}$ \\
\hline Resistance exercise & $\begin{array}{l}-0.32 \\
(-0.60,-0.04)^{55}\end{array}$ & $\begin{array}{l}0.03 \\
(-0.02,0.08)^{55}\end{array}$ & $\begin{array}{l}0.00 \\
(-0.4 I, 0.4 I)^{55}\end{array}$ & $\begin{array}{l}-0.09(\mathrm{BMI}) \\
(-0.29,0.1 \mathrm{II})^{55}\end{array}$ & $\begin{array}{l}-2.78 \\
(-7.37,1.81)^{55}\end{array}$ \\
\hline Combined exercise & $\begin{array}{l}-0.74 \\
(-1.13,-0.35)^{55}\end{array}$ & $\begin{array}{l}0.08 \\
(0.05,0.12)^{55}\end{array}$ & $\begin{array}{l}-0.27 \\
(-0.62,0.09)^{55}\end{array}$ & $\begin{array}{l}-0.5 \\
(-0.75,-0.26)^{55}\end{array}$ & $\begin{array}{l}-3.15 \\
(-4.77,-1.54)^{55}\end{array}$ \\
\hline
\end{tabular}

Note: Numbers in brackets indicate a $95 \%$ confidence interval of mean difference.

Abbreviations: HbAIc, glycated hemoglobin; HDL, high-density lipoprotein; LDL, low-density lipoprotein; BMI, body mass index.

fixed effect model despite high heterogeneity among the included studies. ${ }^{63}$ It also encompassed only studies longer than 6 months. The article comment further highlighted that very-low-carbohydrate and high-protein diets are not officially recommended because of their unconfirmed longterm effects. ${ }^{63}$ Therefore, these diets were excluded from the cost-effectiveness analysis. ${ }^{51,53}$ Two review articles were published for the low-carbohydrate diet. ${ }^{45,52}$ The included low-carbohydrate studies utilized significantly different dietary interventions (carbohydrate intakes from $>20$ to 166 $\mathrm{g} /$ day) and control diets. No study was conducted with the usual diet control group. Consequently, no clear impact on diabetes risk factors could be established. Since the remaining studies suggested superior effect of the Mediterranean diet, the low-carbohydrate intervention was excluded from the cost-effectiveness analysis. ${ }^{47}$ The vegetarian diets were effective in $\mathrm{HbA} 1 \mathrm{c}$ reduction; however, the published metaanalysis didn't present the impact on the remaining diabetes risk factors..$^{50}$ Vegetarian diet interventions were compared to meat diets, and none utilized the usual diet as comparison. Consequently, vegetarian diets were excluded from the costeffectiveness analysis. The Mediterranean diet was the only intervention that was compared to the usual diet. In the Ajala et al study, the Mediterranean diet effect was assessed to lower HbA1c by $-0.41 \% .{ }^{44}$ However, with random effects model utilization instead of the fixed effect, the $\mathrm{HbA} 1 \mathrm{c}$ reduction amounted to $-0.28 \%$ (using RevMan 5). ${ }^{64}$ Similar effect was also reported in the Carter et al and the Huo et al metaanalyses (random effects model: $-0.31 \%,-0.30 \%$ ). ${ }^{46,48}$ All usual diet comparisons were based on the study of Toobert et al which stated a $-0.40 \% \mathrm{HbAl}$ c reduction, despite some publications reporting $-0.34 \%{ }^{47,48,65}$ Since the Huo et al study (nine studies, 1,178 patients) was the latest published, its reported efficacy was used in the cost-effectiveness analysis as the reported efficacy was similar to other studies and it reported the effects on other diabetes risk factors. ${ }^{48}$ For the blood pressure diet impact, data from Nordmann et al (six trials, 2,650 patients) were used. ${ }^{66}$

Interventions were applied on different age groups and body mass groups with different comorbidities. Intervention effects disappeared after the study conclusion. As noted previously, the obtained intervention efficacies (average with upper and lower confidence interval [CI] 95\% values) on HbA1c, LDL, HDL, weight, and blood pressure are summarized in Table 1.

\section{Exercise lifestyle interventions}

Diabetes patients were generally subjected to aerobic, resistance, and combined exercise interventions. ${ }^{54-62}$ The duration of the intervention session was on average between 30 and 60 minutes, with 2-3 sessions per week and intervention duration of 12 weeks to 2 years. Similarly to diet interventions, the exercise studies were applied to different age groups and body mass groups with different comorbidities. Umpierre et al conducted a meta-analysis to assess the efficacy of aerobic $(-0.73 \% \mathrm{HbA} 1 \mathrm{c})$, resistance $(-0.57 \%)$, and combined training $(-0.51 \%) .{ }^{54}$ However, the aerobic group included patients with higher baseline $\mathrm{HbA} 1 \mathrm{c}$ and with three or more exercise sessions per week which suggested a higher effect. ${ }^{67}$ The impact of baseline HbA1c and the number of sessions was afterwards confirmed by Umpierre et al, stating that each additional training day and baseline $\mathrm{HbAlc}$ unit resulted in $0.3 \%$ lower HbA1c values. ${ }^{61}$ Armstrong et al furthermore specified that the combined exercise efficacy was 
assessed too low. ${ }^{67}$ The latter was confirmed by Hayashino et al, Schwingshackl et al, and Chudyk et al where combined training resulted in highest $\mathrm{HbA} 1 \mathrm{c}$ reduction efficacy in comparison with aerobic and resistance training. ${ }^{55,58,62}$

Hayashino et al and Yang et al published comparable efficacy results for aerobic and resistance training on $\mathrm{HbA} 1 \mathrm{c}$ reduction $(-0.46 \%$ and $-0.32 \%)$ and Chudyk et al published equivalent results of resistance training $(-0.33 \%) .{ }^{55,60,62}$ However, resistance training should not be conducted with resistance bands alone in order to be effective. ${ }^{59}$ Hayashino et al, Yang et al, and Chudyk et al also published comparable results with exercise interventions on lipid profile. ${ }^{55,60,62}$ The largest difference was observed among intervention effects on blood pressure. Hayashino et al published the lowest efficacy effect, which was followed by Figueira et al and Yang et al. ${ }^{55,57,60}$ For the cost-effectiveness analysis, results from the Hayashino et al (41 included studies, 2,808 patients) meta-analysis were utilized because the study included results for all types of exercise interventions. ${ }^{55}$ Table 1 summarizes different intervention efficacies (average with upper and lower CI 95\% values) on HbA1c, LDL, HDL, weight, and blood pressure.

\section{Cost-effectiveness of different medication adherence and lifestyle interventions}

As mentioned earlier, the analysis was conducted on real patient data. The patient demographic data are presented in Table 2. The quality-adjusted life expectancy for all diabetes patients without intervention was 7.769 QALYs.

Table 2 Patients' baseline characteristics used in the long-term simulation $(n=93)$

\begin{tabular}{ll}
\hline Parameter & Value \\
\hline Male & $48(51.6 \%)$ \\
Age (years) & $65.9(7.5)$ \\
Duration of diabetes (years) & $9.7(7.7)$ \\
BMI & $30.4(4.8)$ \\
Smoker & $13(13.9 \%)$ \\
HDL $(\mathrm{mmol} / \mathrm{L})$ & $1.24(0.38)$ \\
LDL $(\mathrm{mmol} / \mathrm{L})$ & $2.31(0.74)$ \\
Systolic BP $(\mathrm{mmHg})$ & $144.4(21.9)$ \\
HbAlc $(\%)$ & $7.78(1.29)$ \\
Heart rate $(\mathrm{bpm})^{*}$ & $76^{*}$ \\
WBC $\left(\times 10^{9} / \mathrm{L}\right)^{*}$ & $6.63^{*}$ \\
Hemoglobin $(\mathrm{g} / \mathrm{dL})^{*}$ & $15.5^{*}$ \\
eGFR $\left(\mathrm{mL} / \mathrm{min} / \mathrm{l} .73 \mathrm{~m}^{2}\right)^{*}$ & $60.9^{*}$
\end{tabular}

Notes: Values are presented as mean (standard deviation) or as frequencies (percentages). *Values obtained from literature and adjusted with internal UKPDS Outcomes model 2 equations for each patient. ${ }^{34-37}$

Abbreviations: BMI, body mass index; HDL, high-density lipoprotein; LDL, lowdensity lipoprotein; HbAlc, glycated hemoglobin; WBC, white blood cells; eGFR, estimated glomerular filtration rate.
All interventions demonstrated higher quality-adjusted survival than the base case without intervention. The highest average survival was estimated with medication adherence intervention (high efficacy), followed by combined exercise, medication adherence (low efficacy), aerobic exercise, the Mediterranean diet, and resistance exercise. The first three interventions with 2-year intervention duration performed $0.061,0.027$, and 0.019 better than the base case without intervention and the ones with 10-year intervention duration performed $0.245,0.119$, and 0.075 better, respectfully. The total lifetime costs were also higher in all the cases, which resulted in an ICER between 9,984 EUR (medication adherence) and 148,424 EUR (resistance exercise). The simulated ICER values per QALY gained, QALY gained, and cost increments for all interventions and duration are presented in Table 3. In Figure 2 ICER values per QALY gained are presented.

Aerobic and resistance intervention exercises present a concave, ICER per QALY gained, graph. Other interventions with the exception of combined exercise also result in a concave ICER chart which is considerably less curved. The chart shape is the result of higher QALY gained after 2 or 5 years of intervention which is more noticeable in the case of interventions with low performance. The ICER shape is also the outcome of natural deaths, which are correlated with intervention costs. With longer duration of type 2 diabetes, the intervention costs still rise, however, not linearly, and fall more with each year (occurrence of predicted natural deaths) of simulation and consequently the ICER value decreases.

\section{Sensitivity analysis}

One-way sensitivity analysis varying complication costs, intervention costs, and discount rates showed that the discount rate had the largest impact on the ICER. The impact of intervention costs was also significant, but the impact of complication costs was minimal.

\section{Discussion}

The results indicate that diabetes medication adherence and lifestyle interventions result in higher quality-adjusted life expectancy. Efficacy and intervention costs are an important factor for intervention cost-effectiveness. Regarding the cost savings aim of the present study, it has to be mentioned that no intervention produced net savings. Therefore, diabetes interventions are effective in the prevention of complications, but not in the reduction of payer burden.

Similar exercise intervention impact was detected previously as well, when the cost-effectiveness of community-based 
Table 3 Estimated QALYs gained (QALYg) and cost increments (EUR) per each intervention compared to option without the intervention and calculated ICER values

\begin{tabular}{|c|c|c|c|c|c|c|c|c|c|c|c|c|}
\hline \multirow[t]{2}{*}{ Intervention duration (years) } & \multicolumn{4}{|c|}{ Estimated QALY gained } & \multicolumn{4}{|c|}{$\begin{array}{l}\text { Estimated cost } \\
\text { increments in EUR }\end{array}$} & \multicolumn{4}{|c|}{ ICER (EUR/QALYg) } \\
\hline & $\mathrm{I}$ & 2 & 5 & 10 & I & 2 & 5 & 10 & $\mathbf{I}$ & 2 & 5 & 10 \\
\hline Medication adherence (high efficacy) & 0.033 & 0.061 & 0.135 & 0.245 & 350 & 668 & $\mathrm{I}, 492$ & 2,447 & 10,602 & II,034 & 11,055 & 9,984 \\
\hline Medication adherence (low efficacy) & 0.015 & 0.019 & 0.046 & 0.075 & 328 & 640 & 1,410 & 2,319 & 21,559 & 34,343 & 30,629 & 30,967 \\
\hline The Mediterranean diet & 0.011 & 0.014 & 0.031 & 0.057 & 233 & 430 & 954 & 1,556 & 21,653 & 30,926 & 31,080 & 27,246 \\
\hline Aerobic exercise & 0.011 & 0.019 & 0.036 & 0.069 & 798 & 1,510 & 3,374 & 5,566 & 70,563 & 77,699 & 92,733 & 80,798 \\
\hline Resistance exercise & 0.009 & 0.012 & 0.023 & 0.05 & 802 & 1,522 & 3,376 & 5,568 & 86,940 & 123,263 & 148,424 & III,847 \\
\hline Combined exercise & 0.012 & 0.027 & 0.063 & 0.119 & 761 & I,503 & 3,350 & 5,515 & 65,630 & 56,386 & 53,265 & 46,411 \\
\hline
\end{tabular}

Abbreviations: ICER, incremental cost-effectiveness ratio; QALYs, quality-adjusted life-years.

physical activity interventions was assessed.$^{68}$ The published QALY gain of different interventions (medication adherence and lifestyle) ranged from 0.014 to 0.14 QALYs, whereas our simulation results ranged from 0.009 to 0.245 QALY gained. ${ }^{68-70}$

While comparing medication adherence intervention cost-effectiveness with previously published data of 9,000 EUR/QALYg, it was found that our efficacy, cost, and patient data regarding this particular intervention were correct. ${ }^{69} \mathrm{~A}$ similar intervention was also conducted on Dutch diabetes patients where the intervention cost-effectiveness resulted in ICER of 14,814 EUR/QALYg in patients with history of cardiovascular diseases and in ICER of 38,243 EUR/QALY in all patients, which is higher than our calculated values in the case of high-efficacy intervention but, however, similar to low efficacy medication adherence. ${ }^{70}$

On the subject of exercise interventions, previously published studies reported cost per QALY outcomes of up to $68,557 \mathrm{USD} / \mathrm{QALYg} .{ }^{68}$ While considering higher intervention costs, the result is similar to our estimated

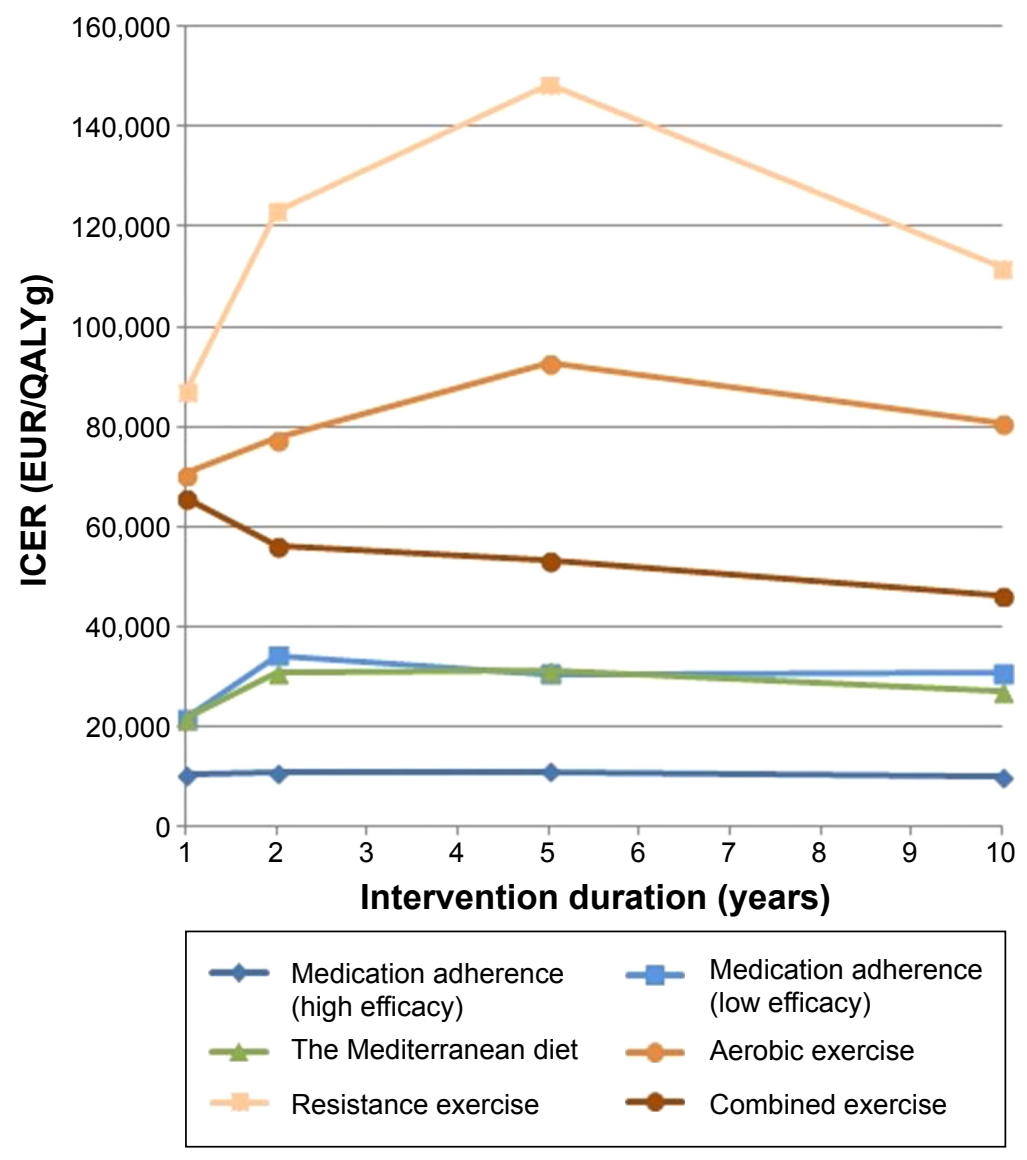

Figure 2 Calculated incremental cost-effectiveness ratio ICER (EUR/QALYg) per each intervention compared to option without the intervention. 
values in exercise intervention cases (from 46,411 to 86,940 EUR/QALYg, excluding results over 100,000 EUR/ QALYg).

While utilizing diabetes-specific nutritional meal replacements as part of the diabetes management program, the outcomes produced an incremental cost-effectiveness output of 47,917 to 50,414 USD/QALYg, whereas our estimated values for diet intervention ranged from 21,653 EUR/QALYg to 31,080 EUR/QALYg. ${ }^{11}$

\section{Limitations}

The present cost-effectiveness diabetes intervention simulation was conducted on real patients. However, the raw data lack values for heart rate, WBC count, hemoglobin, and estimated glomerular filtration rate. Therefore, the simulation could estimate different absolute and possibly smaller relative differences in results. However, with a slight adjustment of average blood risk factor values in individual patients, the possibility of an error was lowered. Complex medication adherence studies also utilized lifestyle counseling among medication adherence education, however, without the usage of any diet and exercise interventions. ${ }^{41}$

The meta-analyses of different interventions were conducted with different effects. The authors used fixed and random effects, meaning that the results are prone to errors. Furthermore, the authors generally did not explain the reasons why which a particular model was used. However, reviews and meta-analyses referenced in Table 1 utilized random effects model for efficacy calculation which was suggested as preferable. ${ }^{63}$

After 1 year of the UKPDS intervention discontinuation, the between-group differences in diabetes risk factor values were lost; however, the intervention effect persisted. ${ }^{13}$ This effect was named "memory effect." ${ }^{13}$ In our simulation, after the conclusion of the intervention, we utilized diabetes risk factors predicted in the base case, meaning that the intervention trend was stopped and the future memory effect was not present because the UKPDS outcomes model does not utilize equations to compensate for the memory effect. It is therefore possible that longer interventions predicted higher complication outcomes.

Unaltered individual patient data from the pharmacist intervention study were used..$^{30}$ The results of this intervention study are presented elsewhere. ${ }^{30}$

\section{Which intervention to choose}

While combining the results from high- and low-efficacy medication adherence intervention studies, the QALY and
EUR/QALYg benefits exceed other interventions, indicating that medication adherence interventions are superior to diet and exercise interventions. However, when higher adherence results in significantly elevated drug costs or co-payments for the patient, then exercise and diet interventions are also important to consider since the literature suggests that with higher drug costs for the patient the adherence could fall. ${ }^{72}$

The study was conducted with published intervention costs and an assumption that interventions need to be supervised. Nevertheless, diet and exercise interventions could also be conducted in patients with no supervision. Hypothetically, the patients could follow proper diet and exercise guidelines on the basis of common self-care which would result in no costs for the Heath Care payer. In the case of medication adherence, lack of supervision is not possible because the process consists of various steps (education sessions, drug reminders, blood tests, self-care reminders, and medication dispensing) where trained personnel are needed.

We should also consider that exercise is probably harder to implement in elderly patients. While examining average age in studies included in the Hayashino et al meta-analysis, most studies included patients $<60$ years with few carried out on patients $>60$ years. ${ }^{55}$ Therefore, it is sensible to implement exercise interventions with younger patients (with low costs), and the diet intervention with the elderly, when medication adherence intervention is not preferred.

The results also indicate that intervention duration $\leq 2$ years results in low ICER values; however, the QALY gained output is also low and similar between all interventions. Consequently, it is reasonable to conduct longer interventions particularly because QALY gains are more noticeable. It is insignificant which duration to choose for combined exercise, the Mediterranean diet, and medication adherence from the ICER standpoint because ICER decreases slightly, whereas for the aerobic and resistance exercise interventions, it is appropriate to choose interventions longer than 5 years because ICER decreases after 5 years of intervention.

\section{Conclusion}

The results suggest that from the payer perspective, medication adherence intervention is cost-effective and is superior to diet and exercise interventions. However, the latter could be utilized by patients without additional costs, whereas medication adherence intervention requires trained personnel because of its complex structure. Interventions should be performed for $>2$ years to produce noticeable health/ cost results. 


\section{Disclosure}

The authors report no conflicts of interest in this work.

\section{References}

1. Shaw JE, Sicree RA, Zimmet PZ. Global estimates of the prevalence of diabetes for 2010 and 2030. Diabetes Res Clin Pract. 2010;87:4-14.

2. Zhang $P$, Zhang X, Brown J, et al. Global healthcare expenditure on diabetes for 2010 and 2030. Diabetes Res Clin Pract. 2010;87:293-301.

3. Koloverou E, Panagiotakos DB, Pitsavos C, et al. 10-Year incidence of diabetes and associated risk factors in Greece: the ATTICA study (2002-2012). Rev Diabet Stud. 2014;11:181-189.

4. Tandon N, Ali MK, Narayan KM. Pharmacologic prevention of microvascular and macrovascular complications in diabetes mellitus: implications of the results of recent clinical trials in type 2 diabetes. Am J Cardiovasc Drugs. 2012;12:7-22.

5. Action to Control Cardiovascular Risk in Diabetes Study Group. Effects of intensive glucose lowering in type 2 diabetes. $N$ Engl J Med 2008;358:2545-2559.

6. Ismail-Beigi F, Craven T, Banerji MA, et al. Effect of intensive treatment of hyperglycaemia on microvascular outcomes in type 2 diabetes: an analysis of the ACCORD randomised trial. Lancet. 2010;376: 419-430.

7. ADVANCE Collaborative Group. Intensive blood glucose control and vascular outcomes in patients with type 2 diabetes. $N$ Engl J Med. 2008;358:2560-2572.

8. Beulens JW, Patel A, Vingerling JR, et al. Effects of blood pressure lowering and intensive glucose control on the incidence and progression of retinopathy in patients with type 2 diabetes mellitus: a randomised controlled trial. Diabetologia. 2009;52:2027-2036.

9. Duckworth W, Abraira C, Moritz T, et al. Glucose control and vascular complications in veterans with type 2 diabetes. $N$ Engl J Med. 2009; 360:129-139.

10. Riddle MC, Ambrosius WT, Brillon DJ, et al. Epidemiologic relationships between $\mathrm{A} 1 \mathrm{C}$ and all-cause mortality during a median 3.4-year follow-up of glycemic treatment in the ACCORD trial. Diabetes Care. 2010;33:983-990.

11. UK Prospective Diabetes Study (UKPDS) Group. Intensive bloodglucose control with sulphonylureas or insulin compared with conventional treatment and risk of complications in patients with type 2 diabetes (UKPDS 33). Lancet. 1998;352:837-853.

12. UK Prospective Diabetes Study (UKPDS) Group. Effect of intensive blood-glucose control with metformin on complications in overweight patients with type 2 diabetes (UKPDS 34). Lancet. 1998;352: 854-865.

13. Holman RR, Paul SK, Bethel MA, Matthews DR, Neil HA. 10-Year follow-up of intensive glucose control in type 2 diabetes. $N$ Engl J Med. 2008;359;1577-1589.

14. Gerstein HC, Pogue J, Mann JF, et al. The relationship between dysglycaemia and cardiovascular and renal risk in diabetic and non-diabetic participants in the HOPE study: a prospective epidemiological analysis. Diabetologia. 2005;48:1749-1755.

15. Gaede P, Vedel P, Larsen N, Jensen GV, Parving HH, Pedersen O. Multifactorial intervention and cardiovascular disease in patients with type 2 diabetes. $N$ Engl J Med. 2003;348:383-393.

16. Gaede P, Lund-Andersen H, Parving HH, Pedersen O. Effect of a multifactorial intervention on mortality in type 2 diabetes. NEngl J Med. 2008; 358:580-591.

17. Huang XL, Pan JH, Chen D, Chen J, Chen F, Hu TT. Efficacy of lifestyle interventions in patients with type 2 diabetes: a systematic review and meta-analysis. Eur J Intern Med. 2016;27:37-47.

18. Schedlbauer A, Davies P, Fahey T. Interventions to improve adherence to lipid lowering medication. Cochrane Database Syst Rev. 2010;3: CD004371.

19. Matthes J, Albus C. Improving adherence with medication: a selective literature review based on the example of hypertension treatment. Dtsch Arztebl Int. 2014;111:41-47.
20. Grandy S, Fox KM, Hardy E; SHIELD Study Group. Association of weight loss and medication adherence among adults with type 2 diabetes mellitus: SHIELD (Study to Help Improve Early evaluation and management of risk factors Leading to Diabetes). Curr Ther Res Clin Exp. 2013;75:77-82.

21. Hayes AJ, Leal J, Gray AM, Holman RR, Clarke PM. UKPDS Outcomes Model 2: a new version of a model to simulate lifetime health outcomes of patients with type 2 diabetes mellitus using data from the 30 year United Kingdom Prospective Diabetes Study: UKPDS 82. Diabetologia. 2013;56:1925-1933.

22. Palmer AJ, Clarke P, Gray A, et al; Mount Hood 5 Modeling Group. Computer modeling of diabetes and its complications: a report on the Fifth Mount Hood challenge meeting. Value Health. 2013;16:670-685.

23. Shai I, Schwarzfuchs D, Henkin Y, et al. Weight loss with a lowcarbohydrate, Mediterranean, or low-fat diet. NEngl JMed.2008;359(3): 229-241.

24. Esposito K, Maiorino MI, Ciotola M, et al. Effects of a Mediterraneanstyle diet on the need for antihyperglycemic drug therapy in patients with newly diagnosed type 2 diabetes: a randomized trial. Ann Intern Med. 2009;151(5):306-314.

25. Loimaala A, Groundstroem K, Rinne M, et al. Effect of long-term endurance and strength training on metabolic control and arterial elasticity in patients with type 2 diabetes mellitus. Am J Cardiol. 2009;103(7): 972-977.

26. Fullerton B, Erler A, Pöhlmann B, Gerlach FM. Predictors of dropout in the German disease management program for type 2 diabetes. $B M C$ Health Serv Res. 2012;12:8.

27. Kirk A, Leese G. Encouraging physical activity interventions among people with type 2 diabetes. J Diabetes Nurs. 2009;13:26-31.

28. Nam S, Dobrosielski DA, Stewart KJ. Predictors of exercise intervention dropout in sedentary individuals with type 2 diabetes. J Cardiopulm Rehabil Prev. 2012;32:370-378.

29. Benoit SR, Ji M, Fleming R, Philis-Tsimikas A. Predictors of dropouts from a San Diego diabetes program: a case control study. Prev Chronis Dis. 2004;1:A10. Epub 2004 Sep 15.

30. Martinc B. Effect of pharmacist's intervention on glycemic control in type 2 diabetic patients. Presented at: "Preventive measures - the most effective means for controlling diabetes: National Conference on Diabetes Control"; December 12, 2014; Ljubljana, Slovenia. Republic of Slovenia Ministry of Health. Available from: http://www.mz.gov.si/ en/media_room/news/article/670/6912/f6d5fe577cd4459d97c19d207b2a6b0d/. Accessed June 1, 2015.

31. Mrevlje F, Piletič M, Senčar Božič P. Insulin detemir izboljša glikemično urejenost in ima nevtralen učinek na telesno maso v slovenski kohorti raziskave predictive - klinične izkušnje $\mathrm{v}$ Sloveniji [Insulin detemir improves glycemic organization and has a neutral effect on body weight in a cohort Slovenian predictive research - clinical experience in Slovenia]. Zdrav Vestn. 2008;77:699-705. In Slovenian.

32. Andel M, Grzeszczak W, Michalek J, et al; DEPAC Group. A multinational, multi-centre, observational, cross-sectional survey assessing diabetes secondary care in Central and Eastern Europe (DEPAC Survey). Diabet Med. 2008;25(10):1195-1203.

33. Holman RR, Paul SK, Bethel MA, Matthews DR, Neil HA. 10-Year follow-up of intensive glucose control in type 2 diabetes. $N$ Engl J Med. 2008;359:1577-1589.

34. Carnethon MR, Yan L, Greenland P, et al. Resting heart rate in middle age and diabetes development in older age. Diabetes Care. 2008;31: 335-339.

35. Twig G, Afek A, Shamiss A, et al. White blood cells count and incidence of type 2 diabetes in young men. Diabetes Care. 2013;36:276-282.

36. Conway BN, Miller RG, Orchard TJ. Are hemoglobin levels elevated in type 1 diabetes? Diabetes Care. 2010;33:341-343.

37. Rigalleau V, Lasseur C, Perlemoine C, et al. Estimation of glomerular filtration rate in diabetic subjects: Cockcroft formula or modification of diet in renal disease study equation? Diabetes Care. 2005;28:838-843.

38. Nerat T, Kos M. Burden of type 2 diabetes from the healthcare payer perspective in Slovenia. Slovenian J Public Health. 2013;52:162-180. 
39. Slovenian National Institute of Public Health. Drug consume database from 2001 to 2014. Available from: https://partner.zzzs.si/ wps/wcm/connect/94bb0e3f-3d23-4156-926f-47732415acd8/ Zdravila+OZZ+2001_2014_i.xlsx?MOD=AJPERES\&ContentCache= NONE. Accessed December 1, 2015.

40. Oberjé EJ, de Kinderen RJ, Evers SM, van Woerkum CM, de Bruin M. Cost effectiveness of medication adherence-enhancing interventions: a systematic review of trial-based economic evaluations. Pharmacoeconomics. 2013;31(12):1155-1168.

41. Williams JL, Walker RJ, Smalls BL, Campbell JA, Egede LE. Effective interventions to improve medication adherence in type 2 diabetes: a systematic review. Diabetes Manag (Lond). 2014;4:29-48.

42. Dalziel K, Segal L, De lorgeril M. A Mediterranean diet is costeffective in patients with previous myocardial infarction. J Nutr. 2006; 136(7):1879-1885.

43. Müller-Riemenschneider F, Reinhold T, Willich SN. Cost-effectiveness of interventions promoting physical activity. Br J Sports Med. 2009;43: 70-76.

44. Ajala O, English P, Pinkney J. Systematic review and meta-analysis of different dietary approaches to the management of type 2 diabetes. Am J Clin Nutr. 2013;97:505-516.

45. Dyson P. Low carbohydrate diets and type 2 diabetes: what is the latest evidence? Diabetes Ther. 2015;6:411-424.

46. Carter P, Achana F, Troughton J, Gray LJ, Khunti K, Davies MJ. A Mediterranean diet improves HbA1c but not fasting blood glucose compared to alternative dietary strategies: a network meta-analysis. J Hum Nutr Diet. 2014;27(3):280-297.

47. Esposito K, Maiorino MI, Bellastella G, Chiodini P, Panagiotakos D, Giugliano D. A journey into a Mediterranean diet and type 2 diabetes: a systematic review with meta-analyses. BMJ Open. 2015;5(8): e008222.

48. Huo R, Du T, Xu Y, et al. Effects of Mediterranean-style diet on glycemic control, weight loss and cardiovascular risk factors among type 2 diabetes individuals: a meta-analysis. Eur J Clin Nutr. 2015;69(11): 1200-1208.

49. Emadian A, Andrews RC, England CY, Wallace V, Thompson JL. The effect of macronutrients on glycaemic control: a systematic review of dietary randomised controlled trials in overweight and obese adults with type 2 diabetes in which there was no difference in weight loss between treatment groups. Br J Nutr. 2015;114(10):1656-1666.

50. Yokoyama Y, Barnard ND, Levin SM, Watanabe M. Vegetarian diets and glycemic control in diabetes: a systematic review and meta-analysis. Cardiovasc Diagn Ther. 2014;4(5):373-382.

51. Dong JY, Zhang ZL, Wang PY, Qin LQ. Effects of high-protein diets on body weight, glycaemic control, blood lipids and blood pressure in type 2 diabetes: meta-analysis of randomised controlled trials. Br J Nutr. 2013;110(5):781-789.

52. Castañeda-González LM, BacardíGascón M, Jiménez-Cruz A. Effects of low carbohydrate diets on weight and glycemic control among type 2 diabetes individuals: a systemic review of RCT greater than 12 weeks. Nutr Hosp. 2011;26(6):1270-1276.

53. Thomas DE, Elliott EJ. The use of low-glycaemic index diets in diabetes control. Br J Nutr. 2010;104(6):797-802.

54. Umpierre D, Ribeiro PA, Kramer CK, et al. Physical activity advice only or structured exercise training and association with $\mathrm{HbA} 1 \mathrm{c}$ levels in type 2 diabetes: a systematic review and meta-analysis. JAMA. 2011; 305:1790-1799.
55. Hayashino Y, Jackson JL, Fukumori N, Nakamura F, Fukuhara S. Effects of supervised exercise on lipid profiles and blood pressure control in people with type 2 diabetes mellitus: a meta-analysis of randomized controlled trials. Diabetes Res Clin Pract. 2012;98:349-360.

56. Sanz C, Gautier JF, Hanaire H. Physical exercise for the prevention and treatment of type 2 diabetes. Diabetes Metab. 2010;36(5):346-351.

57. Figueira FR, Umpierre D, Cureau FV, et al. Association between physical activity advice only or structured exercise training with blood pressure levels in patients with type 2 diabetes: a systematic review and meta-analysis. Sports Med. 2014;44(11):1557-1572.

58. Schwingshackl L, Missbach B, Dias S, König J, Hoffmann G. Impact of different training modalities on glycaemic control and blood lipids in patients with type 2 diabetes: a systematic review and network metaanalysis. Diabetologia. 2014;57(9):1789-1797.

59. Mcginley SK, Armstrong MJ, Boulé NG, Sigal RJ. Effects of exercise training using resistance bands on glycaemic control and strength in type 2 diabetes mellitus: a meta-analysis of randomised controlled trials. Acta Diabetol. 2015;52(2):221-230.

60. Yang Z, Scott CA, Mao C, Tang J, Farmer AJ. Resistance exercise versus aerobic exercise for type 2 diabetes: a systematic review and meta-analysis. Sports Med. 2014;44(4):487-499.

61. Umpierre D, Ribeiro PA, Schaan BD, Ribeiro JP. Volume of supervised exercise training impacts glycaemic control in patients with type 2 diabetes: a systematic review with meta-regression analysis. Diabetologia. 2013;56(2):242-251.

62. Chudyk A, Petrella RJ. Effects of exercise on cardiovascular risk factors in type 2 diabetes: a meta-analysis. Diabetes Care. 2011;34(5): $1228-1237$.

63. Mann JI, Te morenga L. Diet and diabetes revisited, yet again. Am J Clin Nutr. 2013;97(3):453-454.

64. Review Manager (RevMan) [Computer program]. Version 5.3. Copenhagen: The Nordic Cochrane Centre, The Cochrane Collaboration, 2014.

65. Toobert DJ, Glasgow RE, Strycker LA, et al. Biologic and quality-oflife outcomes from the Mediterranean Lifestyle Program: a randomized clinical trial. Diabetes Care. 2003;26(8):2288-2293.

66. Nordmann AJ, Suter-Zimmermann K, Bucher HC, et al. Meta-analysis comparing Mediterranean to low-fat diets for modification of cardiovascular risk factors. Am J Med. 2011;124:841-851.

67. Armstrong MJ, Boulé NG, Sigal RJ. Exercise interventions and glycemic control in patients with diabetes. JAMA. 2011;306(6):607.

68. Roux L, Pratt M, Tengs TO, et al. Cost effectiveness of community-based physical activity interventions. Am J Prev Med. 2008;35:578-588.

69. Jacobs-van der Bruggen MA, van Baal PH, Hoogenveen RT, et al. Cost-effectiveness of lifestyle modification in diabetic patients. Diabetes Care. 2009;32:1453-1458.

70. Cleveringa FG, Welsing PM, van den Donk M, et al. Cost-effectiveness of the diabetes care protocol, a multifaceted computerized decision support diabetes management intervention that reduces cardiovascular risk. Diabetes Care. 2010;33:258-263.

71. Randolph S, Mustad VA, Lee J, Sun J. Economic analysis of a diabetesspecific nutritional meal replacement for patients with type 2 diabetes. Asia Pac J Clin Nutr. 2010;19:1-7.

72. Simard P, Presse N, Roy L, et al. Persistence and adherence to oral antidiabetics: a population-based cohort study. Acta Diabetol. 2015;52(3): $547-556$. 


\section{Supplementary materials}

The following defined daily doses (DDD) and published

Health Care payer expenses for different anatomic therapeutic groups (ATC) were utilized for the year 2011 and 2014. ${ }^{1}$

ATC code C10AA, C10BA; 2011 901,671 DDD/2014

874,060 DDD; 2011 249,911 euro/2014 92,751 euro

ATC code C09A, C09B, C09C; 2011 1,216,343 DDD/2014

960,862 DDD; 2011 53,797 euro/2014 24,804 euro
ATC code C07; 2011 810,770 DDD/2014 772,186 DDD; 201191,755 euro/2014 70,754 euro

ATC code B01AC06; 2011 8,957,006 DDD/2014 12,843,360 DDD; 2011 529,577 euro/2014 559,528 euro

ATC code A10B; 2011 741,423 DDD/2014 662,937 DDD; 2011 194,237 euro/2014 163,045 euro

ATC code A10A; 2011 471,572 DDD/2014 575,191 DDD; 2011 502,277 euro/2014 577,481 euro.

Table SI Costs used and utility values used in the cost-effectiveness analysis

\begin{tabular}{|c|c|c|c|c|c|}
\hline & \multicolumn{3}{|c|}{2015 costs (EUR) } & \multicolumn{2}{|c|}{ Utility decrement } \\
\hline & \multicolumn{2}{|c|}{ At the time of event } & \multirow{2}{*}{$\begin{array}{l}\text { In subsequent } \\
\text { years } \\
\text { Cost }\end{array}$} & \multirow{2}{*}{$\begin{array}{l}\text { At the time } \\
\text { of event }\end{array}$} & \multirow{2}{*}{$\begin{array}{l}\text { In subsequent } \\
\text { years }\end{array}$} \\
\hline & Fatal cost & Nonfatal cost & & & \\
\hline Ischemic heart disease & $2,094.53$ & $3,646.51$ & 248.01 & 0 & 0 \\
\hline Myocardial infarction & $2,094.53$ & $4,695.21$ & 161.93 & -0.065 & 0 \\
\hline Heart failure & $2,094.53$ & $3,646.51$ & 248.01 & -0.101 & -0.101 \\
\hline Stroke & $2,094.53$ & $5,880.33$ & 134.50 & -0.165 & -0.165 \\
\hline Amputation & $7, \mid 46.88$ & $7, \mid 46.88$ & 598.00 & -0.172 & -0.172 \\
\hline Blindness & & $1,358.00$ & 575.00 & 0 & 0 \\
\hline Renal failure & $35,071.83$ & $35,071.83$ & $35,071.83$ & -0.330 & -0.330 \\
\hline Ulcer & & $2,865.00$ & 104.37 & -0.210 & -0.210 \\
\hline Cost in the absence of complications & 283.40 & & & & \\
\hline
\end{tabular}

\section{Reference}

1. Slovenian National Institute of Public Health. Drug consume database from 2001 to 2014. Available from: https://partner.zzzs.si/wps/wcm/ connect/94bb0e3f-3d23-4156-926f-47732415acd8/Zdravila+OZZ+ 2001_2014_i.xlsx?MOD=AJPERES\&ContentCache=NONE. Accessed December 1, 2015.

\section{Publish your work in this journal}

Patient Preference and Adherence is an international, peer-reviewed, open access journal that focuses on the growing importance of patient preference and adherence throughout the therapeutic continuum. Patient satisfaction, acceptability, quality of life, compliance, persistence and their role in developing new therapeutic modalities and compounds to optimize clinical outcomes for existing disease states are major areas of interest for the journal. This journal has been accepted for indexing on PubMed Central. The manuscript management system is completely online and includes a very quick and fair peer-review system, which is all easy to use. Visit http://www. dovepress.com/testimonials.php to read real quotes from published authors. 